\title{
Efeito do uso de enzimas sobre o desempenho e metabolismo de poedeiras ${ }^{1}$
}

\section{Maurício Tárcio dos Santos Viana ${ }^{2}$, Luiz Fernando Teixeira Albino ${ }^{3}$, Horacio Santiago Rostagno $^{3}$, Eliane Aparecida da Silva ${ }^{4}$, Rodrigo Knop Guazzi Messias ${ }^{4}$, João Paulo Leles Pereira ${ }^{5}$}

\author{
1 Projeto apoiado pelo CNPq. \\ 2 Pós-graduação em Zootecnia - Universidade Federal de Viçosa, DZO - UFV, Viçosa, MG. Bolsista CNPq. \\ ${ }^{3}$ Departamento de Zootecnia, UFV - 36571-000 - Viçosa, MG. \\ ${ }^{4}$ Pós-graduação em Zootecnia, UFV - 36571-000 - Viçosa, MG. \\ ${ }^{5}$ Curso de graduação em Zootecnia, UFV - 36571-000 - Viçosa, MG.
}

RESUMO - Objetivou-se verificar o efeito da adição do complexo enzimático (CE) sobre o desempenho e o metabolismo de poedeiras. Foram utilizadas 216 poedeiras da linhagem Bovans Goldline, distribuídas em delineamento experimental inteiramente casualizado, com 12 repetições de seis aves por unidade experimental e 3 tratamentos: controle positivo; controle negativo; e controle negativo + Rovábio ${ }^{\circledR}$ Max $(100 \mathrm{~g} / \mathrm{t})$. A dieta controle positivo foi formulada segundo recomendações das tabelas brasileiras e a dieta controle negativo foi calculada reduzindo os nutrientes presentes na matriz nutricional da enzima de acordo com a empresa produtora. Avaliaram-se o consumo de ração, a produção de ovos, o peso dos ovos, a massa de ovo, a conversão por massa de ovo, a conversão alimentar por dúzia (CAD) e os componentes do ovo no período de 24 a 36 semanas de idade. No ensaio de metabolismo, calcularam-se os valores do coeficiente de digestibilidade da matéria seca, da energia metabolizável aparente (EMA) e da energia metabolizável corrigida (EMAn), bem como seus coeficientes de metabolizabilidade e a retenção de nitrogênio e do balanço de P e Ca das dietas. Nas aves mantidas com a dieta controle negativo, a adição de complexo enzimático na dieta melhorou o percentual de postura e a conversão alimentar por dúzia. A redução dos níveis nutricionais das dietas resultou em menores valores de EMA e EMAn. A suplementação de complexo enzimático às dietas com menores níveis nutricionais melhorou os valores de EMA, resultando em valores similares aos obtidos nas aves alimentadas com a ração controle positivo. Poedeiras alimentadas com a ração controle positivo apresentam maior ingestão, excreção e retenção de fósforo (mg/ave/dia), entretanto, quando a ração é suplementada com complexo enzimático, ocorre maior retenção de fósforo pelas aves.

Palavras-chave: digestibilidade, energia metabolizável, fósforo, metabolizabilidade, ovos

\section{Effect of the use of enzymes on the performance and metabolism of laying hens}

\begin{abstract}
The effect of the addition of multienzymatic complex on performance and metabolism of laying hens was estimated. Two hundred and sixteen Bovans Goldline hens were assigned to a completely randomized design, with 12 replicates of 6 birds per unit and three experimental treatments arranged as follows: positive control (PC), negative control (NC), NC + Rovábio ${ }^{\circledR}$ Max $(100 \mathrm{~g} / \mathrm{t})$. The positive control diets were formulated to contain adequate levels of nutrients according to the recommendations of the Brazilian tables. Diets of NC and NC + Rovábio ${ }^{\circledR}$ Max were calculated with reduced contents of nutrients present in the nutritional contribution of the enzyme complex evaluated according to the recommendations from the manufacturer. The parameters evaluated were: feed intake, egg production, egg weight, egg mass, feed:gain ratio (per g of egg mass and per dozen of egg) in the period from 24 to 36 weeks of age. In the metabolism trial, feed intake and total excreta production per replicate were measured to determine the metabolizable energy values (apparent $\mathrm{ME}$ and apparent Nitrogen Corrected MEn), metabolizability coefficients of gross energy and nitrogen retention and P and Ca balance. When compared to hens fed both negative and positive control diets, the addition of Rovábio ${ }^{\circledR}$ Max to the NC diet improved the hen day egg production an the feed:gain ratio $(\mathrm{kg} / \mathrm{dz})$. The reduction in the levels of nutritional diets resulted in lower ME and MEn values. The supplementation of the enzyme complex to diets with lower nutritional levels improved the ME values, resulting in values similar to those presented by hens fed PC diet. The addition of the enzyme complex to the NC diet increase P retention and resulte in lower P excretion when compared to the hens fed NC diet. Layers fed PC diet show higher $\mathrm{P}$ intake, excretion and retention.
\end{abstract}

Key Words: digestibility, eggs, metabolizability, metabolizable energy, phosphorus 


\section{Introdução}

A necessidade de se melhorar o desempenho das aves objetivando reduzir os custos de produção tem motivado alguns pesquisadores ao estudo de determinadas práticas, principalmente aquelas relacionadas a programas nutricionais, buscando adequar economicamentea adição de enzimas nas rações (Garcia, 1997).

No Brasil, as rações para aves são formuladas principalmente à base de milho e farelo de soja, que representam cerca de $90 \%$ da dieta, contribuindo substancialmente para satisfazer as necessidades em energia, proteínas, minerais e vitaminas de acordo com as tabelas e recomendações das empresas fornecedoras das linhagens existentes no mercado.

Uma boa alimentação deve conter alimentos com ótima digestibilidade, entretanto, os alimentos vegetais apresentam em sua composição bromatológica constituintes denominados polissacarídeos não-amiláceos (PNA), que aumentam a viscosidade intestinal, dificultando a ação das enzimas endógenas e a absorção; além dos fitatos, que indisponibilizam minerais, principalmente os metais bivalentes (Guenter, 1993).

Segundo Pack \& Bedford (1997), uma das alternativas para obtenção de resultados mais favoráveis é o uso de enzimas exógenas na alimentação. Essas enzimas provocam ruptura das paredes celulares das fibras, redução da viscosidade, diminuição dos fatores antinutricionais, melhora da produção das enzimas endógenas do animal, da digestibilidade e da absorção dos nutrientes.

O fato de as enzimas serem específicas em suas reações determina que os produtos que tenham só uma enzima sejam insuficientes para produzir o máximo benefício. Isso sugere que misturas de enzimas sejam mais efetivas no aproveitamento dos nutrientes das dietas. Assim, vários estudos vêm sendo realizados com a adição de enzimas exógenas, sobretudo na forma de "complexo multienzimático".

Para os PNA, existem vários complexos enzimáticos com efeitos sobre a digestão de arabinoxilanos, compostos por pentosanas e $\alpha$-glucanos. No caso dos fitatos, a enzima fitase tem se mostrado muito eficaz na liberação do fósforo da estrutura anelada do fitato, bem como dos minerais citados como cálcio, zinco, ferro e manganês (Bertechini, 2007).

Portanto, este trabalho foi conduzido com o objetivo de avaliar a adição do complexo multienzimático contendo $\beta$-glucanases, xilanases, pectinases, proteases e fitase, em dietas à base de milho e farelo de soja, sobre o desempenho e metabolismo de poedeiras.

\section{Material e Métodos}

Dois experimentos foram conduzidos no Setor de Avicultura do Departamento de Zootecnia da Universidade Federal de Viçosa no período de 26 de abril a 18 de julho de 2007. Inicialmente as aves foram selecionadas de acordo com o peso corporal para uniformização do lote e, por um período de quatro semanas, a produção foi controlada individualmente para posterior redistribuição para equalização da produção.

No experimento 1 , foram utilizadas 216 poedeiras da linhagem Bovans Goldline, de 24 a 36 semanas de idade, durante três períodos experimentais de 28 dias. As aves foram alojadas em um galpão de alvenaria com cobertura de telhas de barro em duas águas, telado, com pé-direito de 2,0 m e composto internamente por gaiolas de arame galvanizado com quatro compartimentos de $25 \times 45 \times 40 \mathrm{~cm}$, distribuídas lateralmente em dois andares, distantes $0,80 \mathrm{~m}$ do piso. O comedouro e bebedouro utilizado foram do tipo calha galvanizada, percorrendo toda extensão frontal das gaiolas.

Durante todo o período experimental, a temperatura no interior do galpão foi monitorada diariamente, duas vezes ao dia (8 e 16h), por meio da utilização de termômetros de máxima e mínima. As aves receberam ração e água à vontade e, 17 horas de luz/dia durante todo o período experimental, respeitando as recomendações de manejo do manual da linhagem. Os ovos foram colhidos duas vezes ao dia ( 8 e $16 \mathrm{~h}$ ), com anotação, em fichas apropriadas, da freqüência de postura e da mortalidade.

O delineamento experimental utilizado foi inteiramente casualizado em três tratamentos, com 12 repetições de 6 aves por unidade experimental. Os tratamentos consistiram de três dietas: controle positivo, formulada conforme recomendações das Tabelas Brasileiras; controle negativo; e controle negativo + Rovábio ${ }^{\circledR} \operatorname{Max}(100 \mathrm{~g} / \mathrm{t})$.

A dieta controle positivo (Tabela 1) foi formulada à base de milho e farelo de soja, segundo recomendações de Rostagno et al. (2005). As dietas controle negativo e controle negativo + complexo enzimático foram calculadas reduzindo $50 \mathrm{kcal} / \mathrm{kg}$ de energia metabolizável, 1,5\% de proteína bruta, 0,08\% de cálcio, 0,1\% de fósforo disponível e de 1,5\% de aminoácidos presentes na matriz nutricional do complexo enzimático (Rovábio ${ }^{\circledR}$ Max $(100$ g/t) de acordo com as recomendações da Adisseo.

As características de desempenho avaliadas foram: consumo de ração (em g/ave/dia) - determinado pela diferença entre peso da ração fornecida e o peso da sobra de ração nos comedouros e recipientes (cálculo realizado a cada período de 28 dias); produção de ovos - a cada período 
Tabela 1 - Composição das dietas experimentais

\begin{tabular}{|c|c|c|}
\hline & Controle positivo & Controle negativo \\
\hline Milho & 62,372 & 64,594 \\
\hline Farelo de soja (45\%) & 23,675 & 23,068 \\
\hline Óleo & 2,806 & 1,506 \\
\hline Fosfato bicálcico & 1,343 & 0,798 \\
\hline Calcário & 8,894 & 9,035 \\
\hline Sal comum & 0,483 & 0,483 \\
\hline DL-metionina (99\%) & 0,209 & 0,198 \\
\hline L-lisina $(78,5 \%)$ & 0,008 & 0,008 \\
\hline Premix vitamínico ${ }^{1}$ & 0,100 & 0,100 \\
\hline Premix mineral $^{2}$ & 0,050 & 0,050 \\
\hline Cloreto de colina (60\%) & 0,050 & 0,050 \\
\hline Antioxidante ${ }^{3}$ & 0,010 & 0,010 \\
\hline Amido $^{4}$ & - & 0,100 \\
\hline \multicolumn{3}{|c|}{ Composição nutricional calculada } \\
\hline $\begin{array}{l}\text { Energia metabolizável } \\
(\mathrm{kcal} / \mathrm{kg})\end{array}$ & $2.900(2900)^{5}$ & $2.850(2850)^{5}$ \\
\hline Proteína bruta (\%) & $16,00(16,00)$ & $15,76(15,76)$ \\
\hline Cálcio (\%) & $3,820(3,820)$ & $3,740(3,740)$ \\
\hline Fósforo disponível (\%) & $0,341(0,341)$ & $0,241(0,241)$ \\
\hline Lisina digestível (\%) & $0,741(0,741)$ & $0,730(0,730)$ \\
\hline Met + Cis digestível (\%) & $0,674(0,674)$ & $0,664(0,664)$ \\
\hline Metionina digestível (\%) & $0,443(0,371)$ & $0,432(0,365)$ \\
\hline Treonina digestível (\%) & $0,540 \quad(0,489)$ & $0,537(0,482)$ \\
\hline Triptofano digestível (\%) & $0,170 \quad(0,170)$ & $0,167(0,167)$ \\
\hline Arginina digestível (\%) & $0,982(0,741)$ & $0,971(0,730)$ \\
\hline Isoleucina digestível (\%) & $0,617(0,615)$ & $0,611(0,606)$ \\
\hline Valina digestível (\%) & $0,675(0,667)$ & $0,671 \quad(0,657)$ \\
\hline \multicolumn{3}{|c|}{ 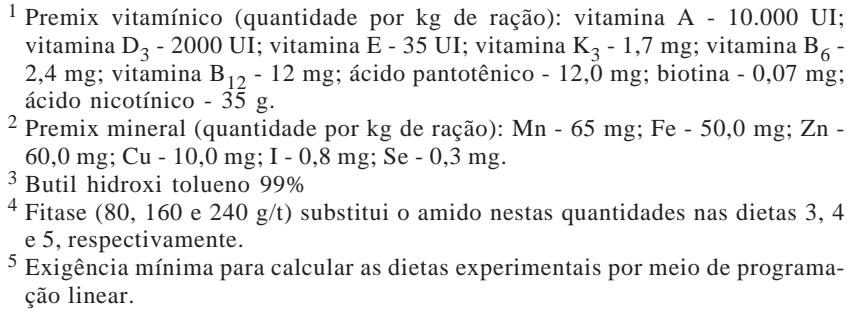 } \\
\hline
\end{tabular}

de 28 dias, foram calculadas as porcentagens de ovos/ave/dia, dividindo-se o total de ovos produzidos pelo número de aves de cada parcela, e pelo número de dias vezes 100; peso dos ovos - todos os ovos íntegros nos cinco últimos dias de cada período experimental foram pesados para o cálculo do peso médio dos ovos; massa de ovos (g/ave/dia) calculada como o produto da porcentagem de ovos/ave/dia e do peso médio dos ovos em cada parcela, dentro de cada período de 28 dias; a conversão alimentar por massa de ovos, calculada pela relação entre grama de ração ingerida pelas aves e massa de ovo produzida em gramas; conversão alimentar por dúzia de ovos - calculada pela relação entre a quantidade de ração consumida $(\mathrm{kg})$ por dúzia de ovo produzida em cada parcela; e ganho de peso - obtido pela diferença dos pesos das aves no início e no final do experimento.

Para obtenção dos componentes do ovo, foram avaliados os pesos de gema, do albúmen e da casca utilizando-se seis ovos de cada repetição, coletados aleatória e diariamente do total de ovos coletados nos três últimos dias de cada período. Os ovos de cada repetição e de cada dia foram pesados individualmente em balança com precisão de $0,001 \mathrm{~g}$ e, após as pesagens, foram identificados e quebrados. A gema de cada ovo foi pesada e a respectiva casca foi lavada e seca ao ar para posterior obtenção do peso da casca sem a membrana interna. O peso do albúmen foi calculado como a diferença entre o peso do ovo e os pesos da gema e da casca.

No ensaio de metabolismo (experimento 2), utilizaram-se, simultaneamente, as 216 poedeiras com 33 semanas de idade do experimento 1 , portanto, manteve-se o mesmo delineamento adotado no experimento de desempenho.

As dietas fornecidas foram pesadas no início e no final do período total de coleta com a finalidade de se obterem o consumo médio de ração e a energia bruta consumida em cada tratamento.

Sob as gaiolas foram colocadas bandejas metálicas revestidas com plástico para permitir a coleta das excretas, que foi feita diariamente, em intervalos de 8 horas, durante cinco dias.

As excretas recolhidas em cada unidade experimental, após a eliminação de penas, resíduos de ração e outras fontes de contaminação, foram transferidas para sacos plásticos devidamente identificados, pesadas e armazenadas em freezer a $-12{ }^{\circ} \mathrm{C}$. Posteriormente, foram descongeladas, reunidas por repetição, homogeneizadas, retirando-se uma alíquota de $400 \mathrm{~g}$, que foi mantida em estufa de ventilação forçada por 72 horas a $55^{\circ} \mathrm{C}$, para secagem. Em seguida, foram expostas ao ar, para entrar em equilíbrio com a temperatura e umidade do ambiente, sendo posteriormente pesadas, moídas e acondicionadas para as análises.

Foram anotadas as quantidades de ração consumidas e de excretas produzidas. As análises laboratoriais de matéria seca, nitrogênio e fósforo, das rações e das excretas seguiram a metodologia descrita por Silva (1990).

Todas as análises foram realizadas em duplicatas no Laboratório de Nutrição Animal do Departamento de Zootecnia da UFV. Os valores de energia bruta (EB) foram determinados por meio de bomba calorimétrica adiabática Parr.

Após a obtenção dos resultados das análises laboratoriais das dietas e das excretas, foram calculados os coeficientes de digestibilidade aparente da matéria seca, energia metabolizável aparente (EMA) e energia metabolizável corrigida (EMAn), bem como seus respectivos coeficientes de metabolizabilidade; além do balanço de nitrogênio. O 
coeficiente de metabolizabilidade indica a porcentagem de energia bruta metabolizada na forma de EMA e EMAn, calculada utilizando-se os valores de energia metabolizável divididos pela energia bruta referente a cada tratamento. Determinaram-se também os valores médios de ingestão, de excreção e de retenção aparente de fósforo e cálcio.

As avaliações estatísticas de ambos os experimentos foram feitas utilizando-se análise de variância (Anova) com comparação de médias pelo teste de StudentNewman-Keul (SNK), a 5\% de probabilidade, utilizando o software SAEG (UFV, 2000).

\section{Resultados e Discussão}

Comparando as aves que receberam dietas controle positivo e negativo, a adição do Rovábio ${ }^{\circledR}$ Max na dieta controle negativo melhorou $(\mathrm{P}<0,05)$ a porcentagem de postura e a conversão alimentar por dúzia (CAD). Em porcentagem, esse aumento com a adição do complexo multienzimático nos dois parâmetros foi de 3,0\% (controle negativo + complexo enzimático vs controle negativo) e 2,4\% (controle negativo + complexo enzimático vs controle positivo) (Tabela 2).

A redução do nível de energia das dietas geralmente ocasiona aumento do consumo de ração (CR) e piora a conversão alimentar (CA), provavelmente porque, com a redução do nível de energia nas dietas, as aves passam a se alimentar mais para manterem o nível diário de ingestão de energia (Leeson, 1999). Todavia, neste estudo, as aves mantidas com as dietas controle positivo e controle negativo tiveram desempenho semelhante $(\mathrm{P}>0,05)$ em todos os parâmetros estudados, provavelmente em virtude da pequena diferença em conteúdo de nutriente (1,7\% EM e $1,5 \% \mathrm{AA})$.

Soto-Salanova et al. (1996), em ensaio realizado para verificar o desempenho de frangos alimentados com rações à base de milho e farelo de soja, contendo baixos teores de energia e aminoácidos, com e sem adição de enzima, também não encontraram diferença no consumo e na conversão alimentar entre as dietas e concluíram que a adição de enzima aumenta o valor nutritivo da dieta, proporcionando desempenho semelhante àquela com formulação normal.

Mentem et al. (2008), em experimento com frangos de corte no período de 1 a 21 dias de idade, observaram que as aves mantidas com dietas suplementadas com Rovábio ${ }^{\circledR} M a x$ apresentaram consumo de ração e conversão alimentar $(\mathrm{P}<0,05)$ semelhantes àqueles obtidos no controle positivo.

Yu \& Chung (2004) verificaram que a adição de níveis adequados de $\alpha$-amilase, $\beta$-glucanase e xilanase em dietas com redução de 3\% de EM para frangos de corte resultou em desempenho semelhante ao obtido com dieta controle.

No entanto, Fischer et al. (2002), estudando dietas à base de milho e farelo de soja, superestimadas em $5 \%$ de energia, proteína e aminoácidos, com e sem complexo multienzimático, observaram que o desenvolvimento das aves mantidas com dietas com enzimas não se igualou ao daquelas arraçoadas com dieta normal sem suplementação enzimática.

Com exceção do peso do albúmen e o percentual de casca, não houve diferença estatística $(\mathrm{P}>0,05)$ entre os demais componentes (Tabela 3). Houve aumento na porcentagem de casca com a suplementação do Rovábio ${ }^{\circledR}$ Max, no entanto, não houve diferença estatística $(\mathrm{P}>0,05)$ em relação às poedeiras alimentadas com a dieta controle negativo. De acordo com Leeson \& Summers (2005), existe relação entre o peso do ovo e o peso do albúmen, ou seja, quanto mais leve o ovo, menor o peso do albúmen. Essa informação foi confirmada neste experimento, pois o menor peso do albúmen $(\mathrm{P}<0,05)$ foi obtido com a dieta que promoveu numericamente o menor peso do ovo (controle negativo + complexo enzimático).

A redução dos níveis nutricionais das dietas resultou em menores valores de EMA e EMAn. A suplementação do complexo multienzimático à dieta com menores níveis

Tabela 2 - Desempenho de poedeiras alimentadas com rações suplementadas com complexo enzimático Rovábio ${ }^{\circledR}$ Max no período de 24 a 36 semanas de idade

\begin{tabular}{lcccc}
\hline Característica & & Dieta experimental & Anova & CV (\%) \\
\cline { 2 - 4 } & Controle positivo & Controle negativo & $\begin{array}{c}\text { Controle negativo }+ \\
\text { Rovábio Max }\end{array}$ \\
\hline Consumo de ração (g/ave/dia) & 108,54 & 108,21 & 109,16 & NS \\
Produção de ovos (\%/ave/dia) & $90,81 \mathrm{~B}$ & $90,29 \mathrm{~B}$ & $93,32 \mathrm{~A}$ & 0,016 \\
Peso dos ovos (g) & 60,41 & 60,07 & 2,74 \\
Massa de ovos (g/ave/dia) & 54,83 & 54,29 & 59,36 & 0,134 \\
Conversão alimentar por dúzia (kg/dúzia) & $1,426 \mathrm{~B}$ & $1,436 \mathrm{~B}$ & 2,08 \\
Conversão alimentar por massa de ovos (g/g) & 1,969 & 1,993 & $1,397 \mathrm{~A}$ & 0,318 \\
\hline
\end{tabular}

Médias seguidas de letras distintas na mesma linha diferem $(\mathrm{P}<0,05)$ entre si pelo teste SNK. 
nutricionais melhorou os valores de EMA (Tabela 4), resultando em valores similares aos apresentados pelas aves alimentadas com a ração controle positivo.

Não houve diferença significativa no consumo de ração e no coeficiente de digestibilidade aparente da matéria seca com a suplementação do complexo multienzimático $(\mathrm{P}>0,05)$. Do mesmo modo, não houve efeito significativo $(\mathrm{P}>0,05)$ das dietas sobre os coeficientes de metabolizabilidade da EM e EMn e o balanço de nitrogênio. Não foi observado benefício da adição do complexo multenzimático na dieta controle positivo (Tabela 4).

Poedeiras mantidas com a dieta controle positivo apresentaram maiores ingestão, excreção e retenção de fósforo (mg/ave/dia) (Tabela 5). Este maior valor de $\mathrm{P}$ excretado pode ser explicado pela maior quantidade desse mineral na dieta. Entretanto, houve maior percentual de retenção de fósforo pelas aves que receberam dietas suplementadas com o complexo multienzimático $(\mathrm{P}<0,01)$.

Tabela 3 - Características do ovo de poedeiras alimentadas com rações suplementadas com o complexo enzimático Rovábio ${ }^{\circledR}$ Max no período de 24 a 36 semanas de idade

\begin{tabular}{lcccc}
\hline Característica & & Dieta experimental & Anova \\
\cline { 2 - 4 } & Controle positivo & Controle negativo & $\begin{array}{c}\text { Controle negativo }+ \\
\text { Rovábio Max }\end{array}$ \\
\hline Peso da gema (g) & & & 14,31 & NS \\
Peso da casca (g) & 14,29 & 14,29 & 5,47 & 0,233 \\
Peso do albúmen (g) & 5,45 & 5,55 & $38,65 \mathrm{~B}$ & 0,035 \\
Gema (\%) & $40,07 \mathrm{~A}$ & $39,62 \mathrm{AB}$ & 24,51 & 0,139 \\
Casca (\%) & 23,91 & 24,04 & 3,24 \\
Albúmen (\%) & $9,11 \mathrm{~B}$ & $9,34 \mathrm{~A}$ & 3,09 \\
\hline
\end{tabular}

Médias seguidas de letras distintas na mesma linha diferem $(\mathrm{P}<0,05)$ entre si pelo teste SNK.

Tabela 4 - Consumo de matéria seca, coeficiente de digestibilidade aparente da matéria seca, energia metabolizável aparente e energia metabolizável aparente corrigida das dietas experimentais

\begin{tabular}{|c|c|c|c|c|c|}
\hline \multirow[t]{2}{*}{ Item } & \multicolumn{3}{|c|}{ Dieta experimental } & \multirow[t]{2}{*}{ Anova } & \multirow[t]{2}{*}{ CV $(\%)$} \\
\hline & $\begin{array}{l}\text { Controle } \\
\text { positivo }\end{array}$ & $\begin{array}{l}\text { Controle } \\
\text { negativo }\end{array}$ & $\begin{array}{c}\text { Controle negativo }+ \\
\text { Rovábio Max }\end{array}$ & & \\
\hline Consumo de de matéria seca, MS (g) & 3.110 & 3.230 & 3.239 & 0,235 & 6,29 \\
\hline Coeficiente de digestibilidade aparente da matéria seca (\%) & 74,58 & 75,16 & 75,63 & 0,113 & 1,55 \\
\hline Energia metabolizável aparente, EMA (kcal/kg) & $3.426 \mathrm{~A}$ & $3.376 \mathrm{~B}$ & $3.398 \mathrm{AB}$ & 0,012 & 1,10 \\
\hline Energia metabolizável aparente corrigida, EMAn (kcal/kg) & $3.314 \mathrm{~A}$ & $3.268 \mathrm{~B}$ & $3.288 \mathrm{~B}$ & 0,004 & 0,94 \\
\hline Coeficiente de metabolizabilidade da energia metabolizável (\%) & 81,76 & 81,67 & 82,20 & 0,317 & 1,10 \\
\hline Coeficiente de metabolizabilidade da EMAn (\%) & 79,09 & 79,05 & 79,53 & 0,241 & 0,94 \\
\hline Balanço de nitrogênio (g N retido/ave/dia) & 1,452 & 1,440 & 1,476 & NS & 10,13 \\
\hline
\end{tabular}

Médias seguidas de letras distintas na mesma linha diferem entre si $(\mathrm{P}<0,05)$ pelo teste SNK.

Tabela 5 - Balanço de fósforo e cálcio das dietas experimentais

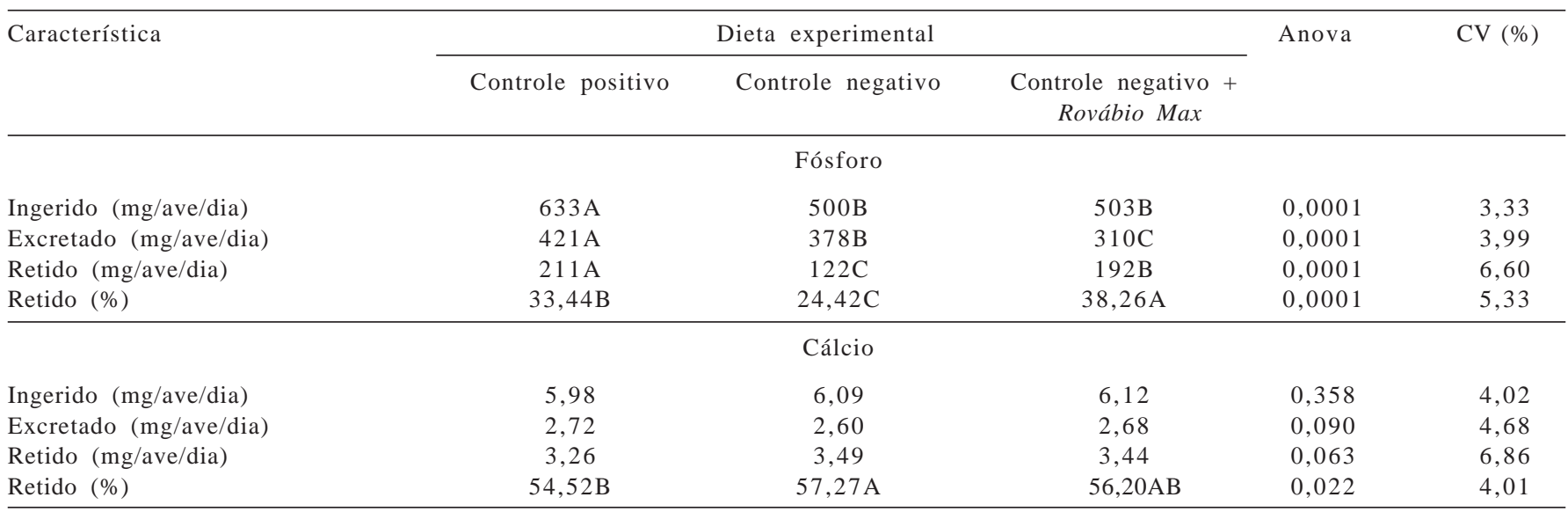

Médias seguidas de letras distintas na mesma linha diferem entre si $(\mathrm{P}<0,05)$ pelo teste SNK. 
A excreção de fósforo foi reduziu com a utilização do complexo multienzimático $(\mathrm{P}<0,01)$. Resultados semelhantes foram encontrados por Wu \& Ravindran (2002), que concluíram que a suplementação do complexo multienzimático em uma dieta à base de milho e farelo de soja com nível subótimo de energia metabolizável e baixo conteúdo de fósforo, reduz a excreção desse mineral sem afetar o desempenho das poedeiras.

Não houve diferença estatística $(\mathrm{P}>0,05)$ entre as dietas para a ingestão, excreção e retenção de cálcio (mg/ave/dia). A suplementação do Rovábio ${ }^{\circledR}$ Max melhorou $(\mathrm{P}<0,05)$ porcentual de retenção de cálcio, mas não diferiu da dieta controle positivo.

\section{Conclusões}

A utilização do complexo multienzimático é eficiente em dietas para poedeiras, pois promove aumento do percentual de postura, redução da conversão alimentar por dúzia e aumento dos valores de energia metabolizável aparente e retenção de fósforo em dietas nutricionalmente deficientes.

\section{Literatura Citada}

BERTECHINI, AA.G.; BRITO, J.A.A. Utilização correta das enzimas em rações de aves. In: FÓRUM INTERNACIONAL DE AVICUlturA, 2., 2007, Curitiba. Anais... Curitiba: 2007. p.237-240.

FISCHER, G.; MAIER, J.C.; RUTZ, F. Desempenho de frangos de corte alimentados com dietas à base de milho e farelo de soja, com ou sem adição de enzimas. Revista Brasileira de Zootecnia, v.31, n.1, p.402-410, 2002.

GARCIA, O. Enzimas: recentes contribuições para a sua aplicação em nutrição animal. In: ENCONTRO DE NUTRIÇÃO
ANIMAL, 3., 1997, São Paulo. Anais... São Paulo: Finnfeeds, 1997. p.1-9.

GUENTER, W. Impact of feed enzymes on nutrient utilization of ingredients in growing poultry. Journal of Applied Poultry Research, v.2, p.82-84, 1993.

LEESON, S. Enzimas para aves. In: SIMPÓSIO INTERNACIONAL SOBRE NUTRIÇÃO DE AVES, 1999, Campinas. Anais... Campinas: Fundação Apinco de Ciência e Tecnologia Avícolas, 1999. p.173-185.

LEESON, S.; SUMMERS, J.D. Commercial poultry nutrition. Guelph: University Books, 2005. 406p.

MENTEN, J.F.M.; RACANICCI, A.M.C.; TRAIDI, A.B. et al. Avaliação da eficácia de complexo enzimático na dieta sobre o desempenho de frangos de corte criados em granja experimental. In: CONFERÊNCIA APINCO DE CIÊNCIAS E TECNOLOGiA AVÍCOLAS, 2008, Santos. Anais... Santos: Fundação Apinco de Ciência e Tecnologia Avícolas, 2008. p.69.

PACK, M.; BEDFORD, M. Feed enzymes for corn-soybean broiler diets. A new concept to improve nutritional value and economics. World Poultry Science Journal, v.13, p.87-93, 1997.

ROTTER, B.A. The future of crude enzyme supplements in pig nutrition. Pig News Information, v.11, n.l, p.15-17, 1990.

SILVA, D.J. Análise de alimentos (métodos químicos e biológicos). Viçosa, MG: Universidade Federal de Viçosa, 1990. 165p.

ROSTAGNO, H.S.; ALBINO, L.F.T.; DONZELE, J.L. et al. Tabelas brasileiras para aves e suínos: composição de alimentos e exigências nutricionais. Viçosa, MG: Universidade Federal de Viçosa, 2005. 186p.

UNIVERSIDADE FEDERAL DE VIÇOSA - UFV. SAEG - Sistema de análises estatísticas e genéticas. Versão 8.0. Viçosa, MG: 2000. 59p. (Manual do usuário).

SOTO-SALANOVA, M.F.; GARCIA, O.; GRAHAM, H. et al. Uso de enzimas em dietas de milho e soja para frangos de corte. In: CONFERÊNCIA APINCO DE CIÊNCIA E TECNOLOGIA AVÍCOLA, 1996, Campinas. Anais... Campinas: Fundação Apinco de Ciência e Tecnologia Avícolas, 1996. p.71-76.

WU, Y.B.; RAVINDRAN, V. Expanding the potential of enzymes to release nutrients: a unique microbial phytase produced by solid state fermentation. In: ALLTECH'S ANNUAL SYMPOSIUM, 18., 2002, Nottingham. Proceedings... Nottingham: Nottingham University Press, 2002. p.123-130.

YU B.I.; CHUNG T.K. Effects of multiple-enzyme mixtures on growth performance of broilers fed corn-soybean meal diets. Journal Applied Poultry Research, v.13, p.178-182, 2004. 